\title{
DIMENSION EFFECTS ON THE ACOUSTIC BEHAVIOUR OF TRC PLATES
}

ir. Nicolas Ospitia

Prof. Dr. ir. Dimitrios Aggelis

Dr. ir. Eleni Tsangouri

\section{(n) \& CONSTRUCTIONS}

\section{ASEC 2020}




\section{ACOUSTIC EMISSION}

\section{LITERATURE REVIEW}

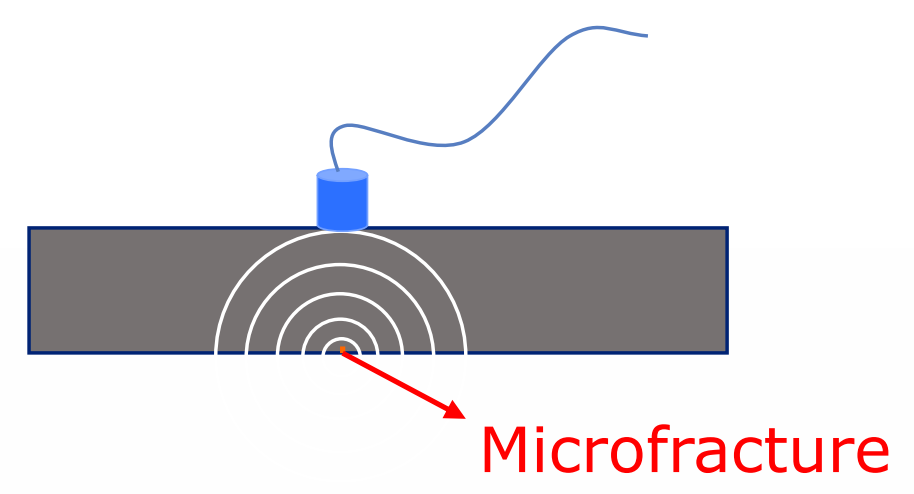

- Average Frequency (AF)

- Duration

- Rise Time (RT)

- Amplitude

- RA value
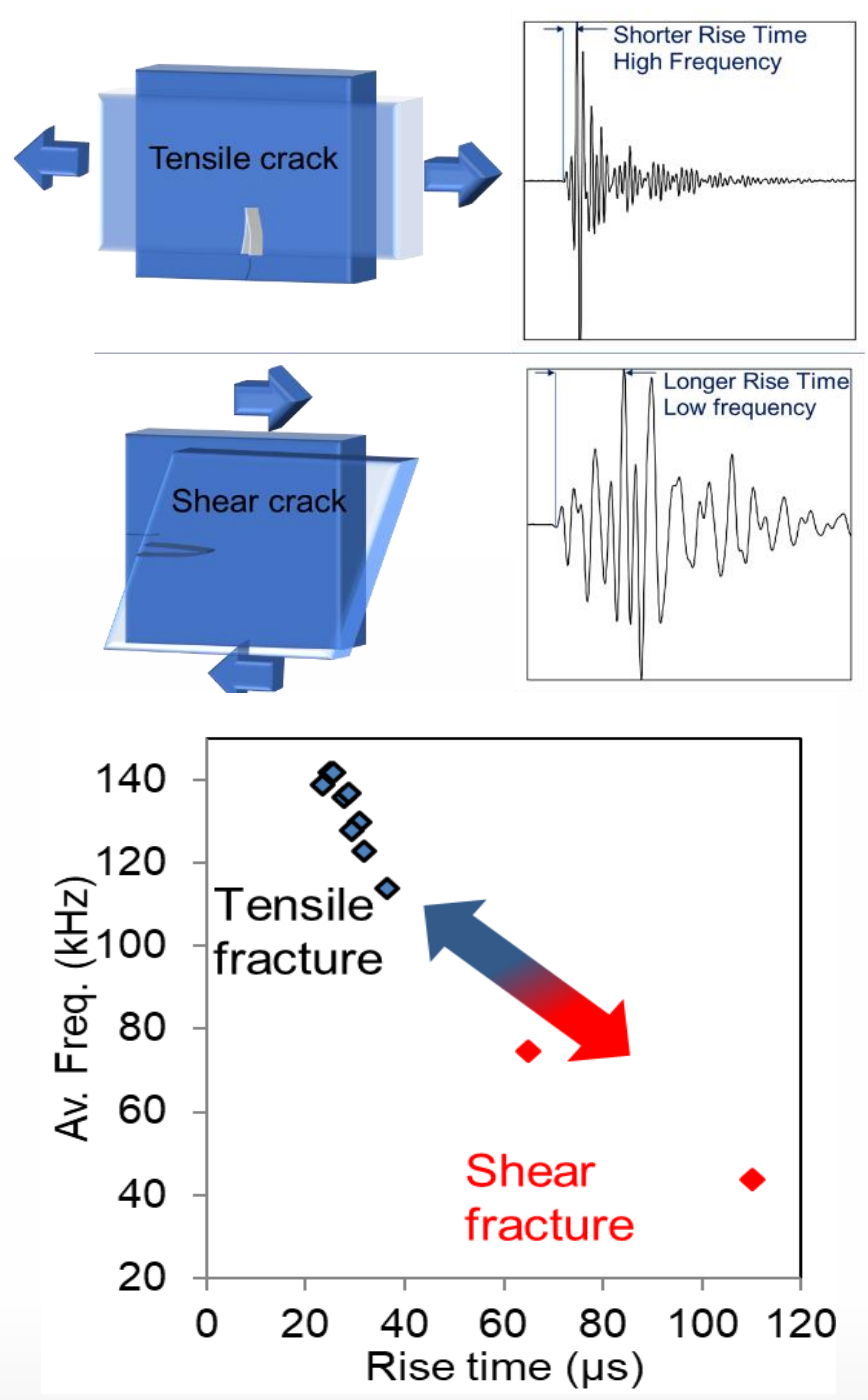


\section{ACOUSTIC EMISSION}

\section{PROBLEM STATEMENT}

Frequency content and waveform shape are severely distorted due to:

- Scattering

- Damping

- Reflections

- Wave dispersion

The present study aims to examine wave propagation from artificial sources and mechanical tests.

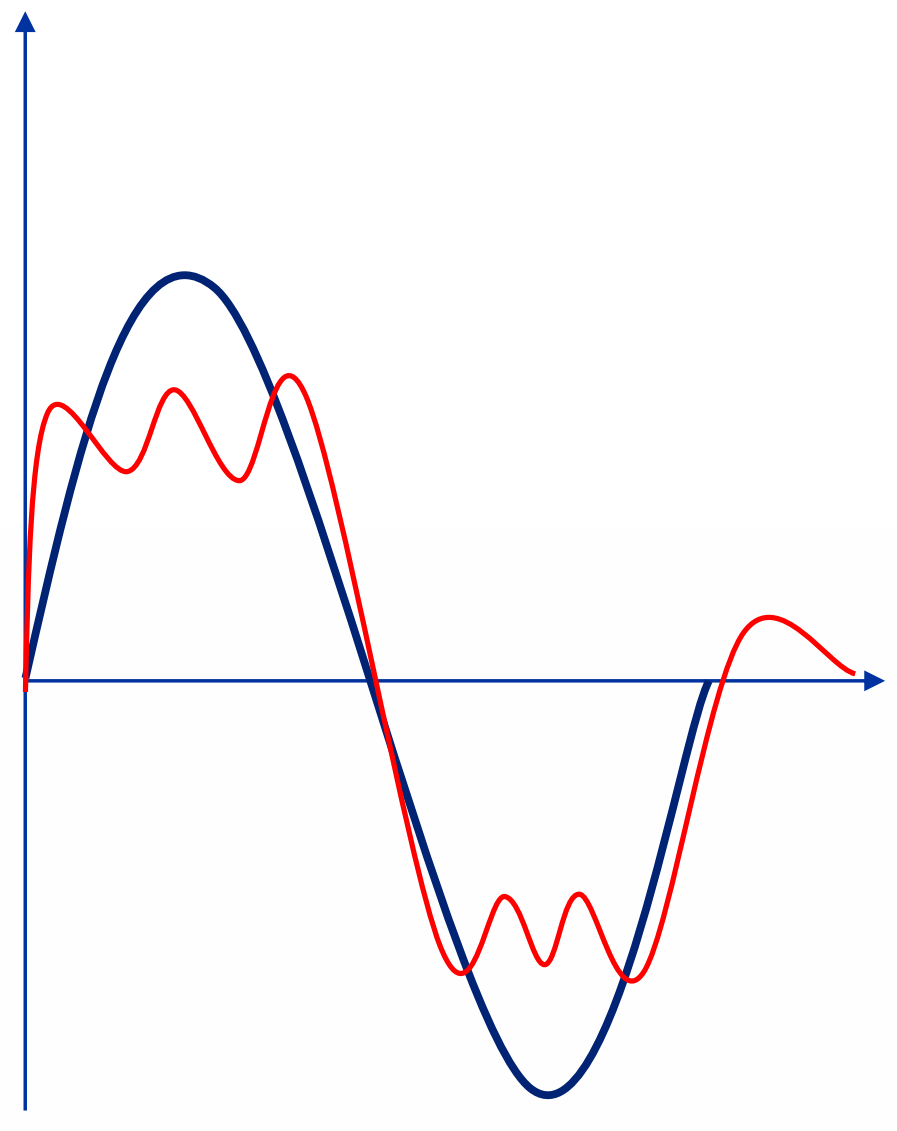




\section{EXPERIMENTAL DETAILS}

MATERIALS

Textile Reinforced Inorganic Phosphate Cement

Reinforcement: E-glass chopped fiber mats $\left(300 \mathrm{~g} / \mathrm{m}^{2}\right)$

Fiber volume fraction: $20 \%$

Plate: $400 \times 400 \times 2.5 \mathrm{~mm}^{2}$

Beam: $400 \times 20 \times 4.5 \mathrm{~mm}^{2}$

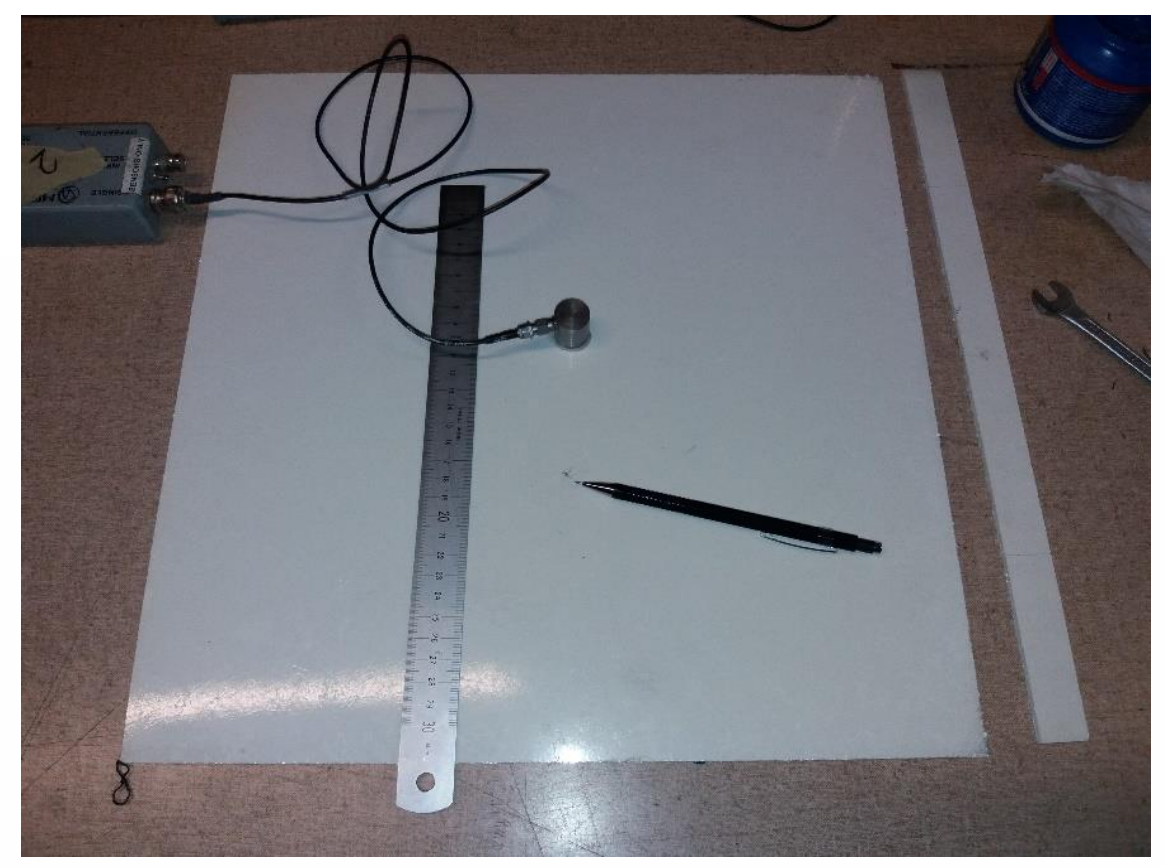




\section{EXPERIMENTAL DETAILS}

\section{WAVE PROPAGATION EXPERIMENTS}

- R15 AE sensors

- Micro-II Digital AE System

- Pencil lead break excitation

- Propagation speed: $2730 \mathrm{~m} / \mathrm{s}$

- Sampling rate $10 \mathrm{MHz}$

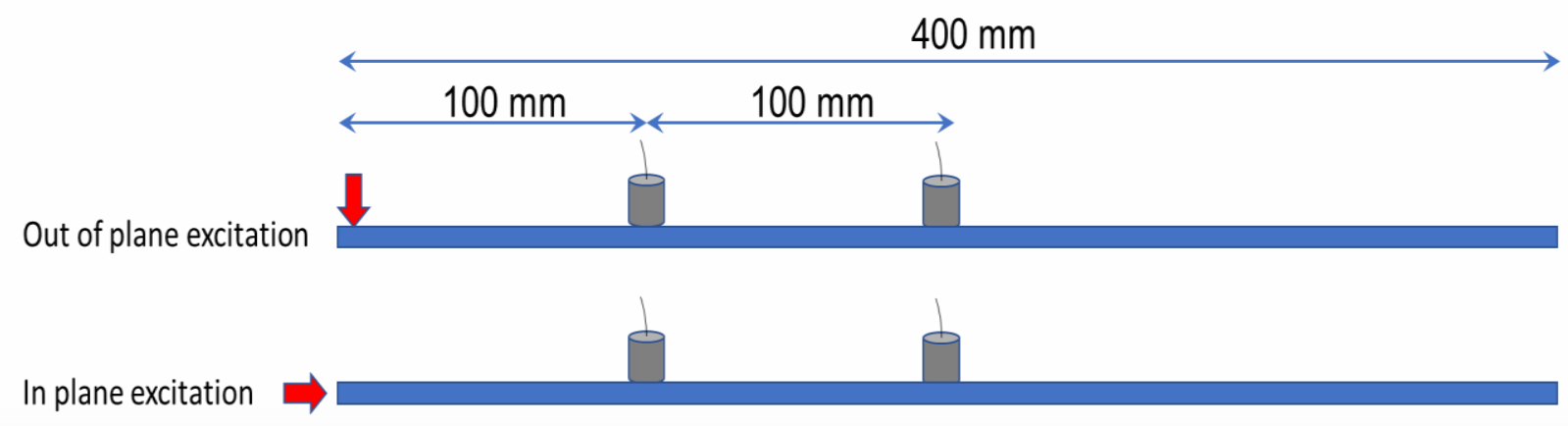

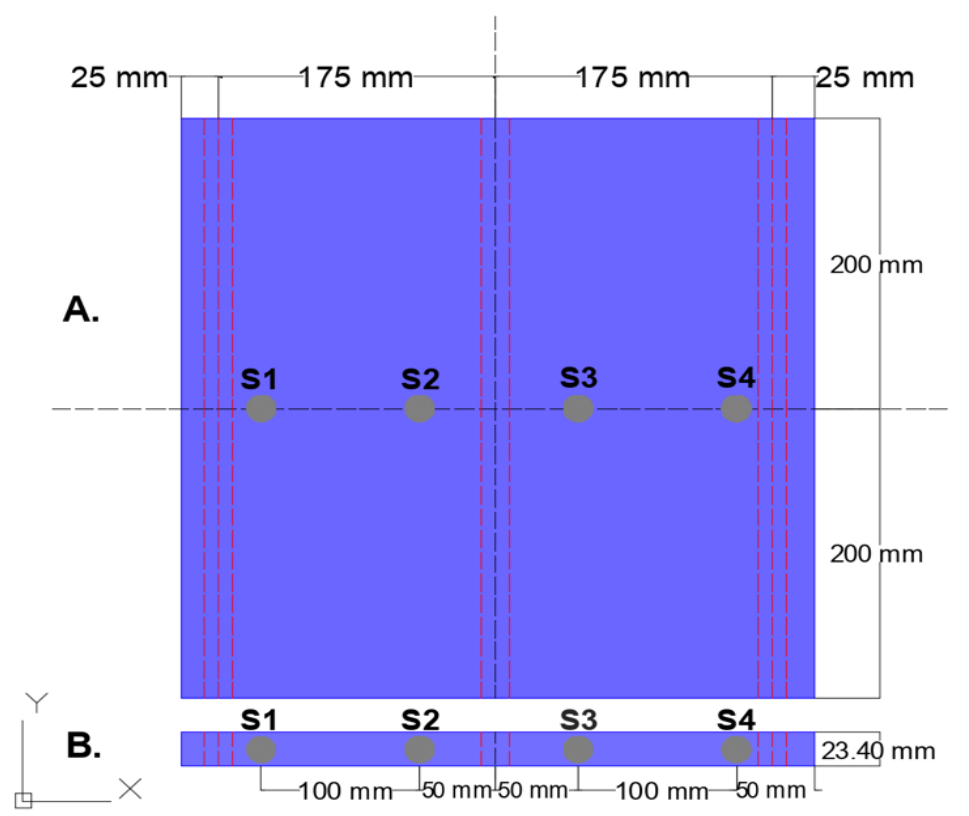

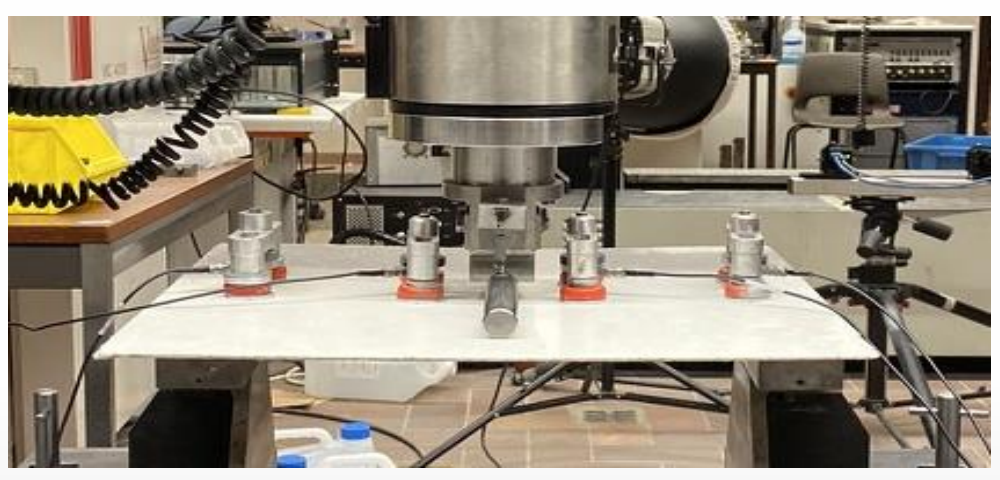




\section{Results}

\section{(1I) MECHANICS OF MATERIALS \& CONSTRUCTIONS}

\section{ASEC 2020}




\section{RESULTS}

\section{ARTIFICIAL EXCITATION}

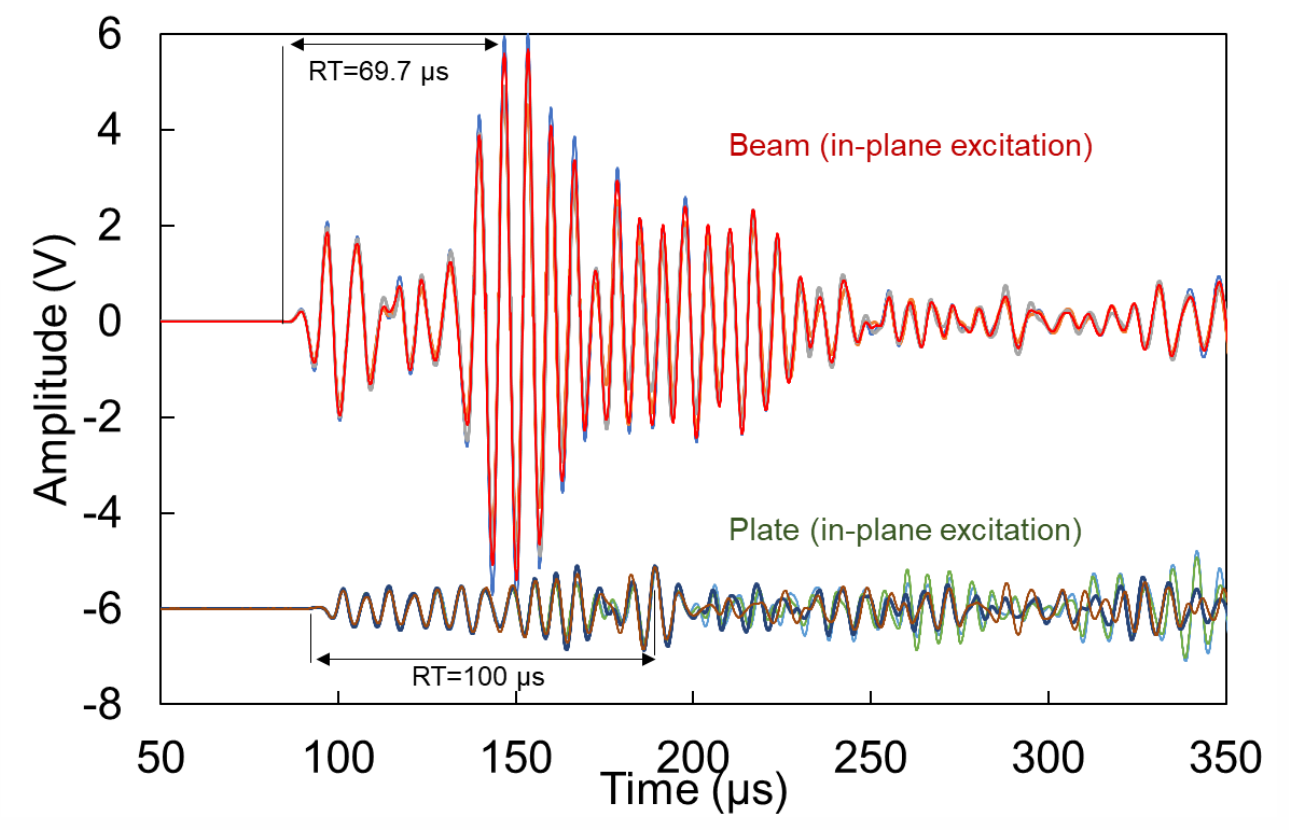

- Simulates a matrix crack

- RT Beam < RT Plate

- A Beam > A Plate

Attributed to the spreading of the energy in the plate geometry, as well as absence of reflections from the edges

$\stackrel{400 \mathrm{~mm} \longrightarrow}{\longleftrightarrow} \stackrel{400 \mathrm{~mm}}{\longleftrightarrow}$




\section{RESULTS}

\section{ARTIFICIAL EXCITATION}

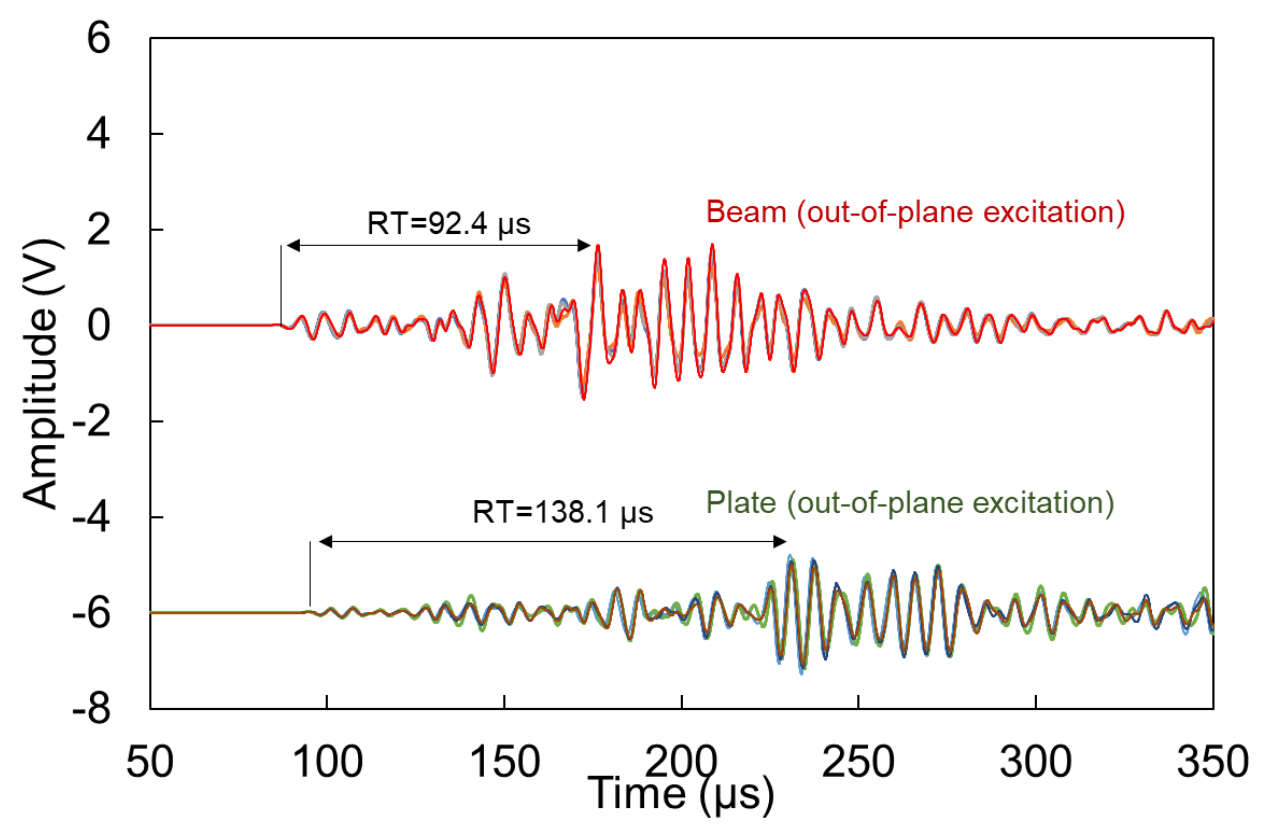

- Dominant "antisymmetric" mode

- RT Beam < RT Plate

- A Beam > A Plate

Attributed to the spreading of the energy in the plate geometry, as well as absence of reflections from the edges

$\stackrel{400 \mathrm{~mm} \longrightarrow}{\longleftrightarrow}$




\section{RESULTS}

\section{DISPERSION CURVE}

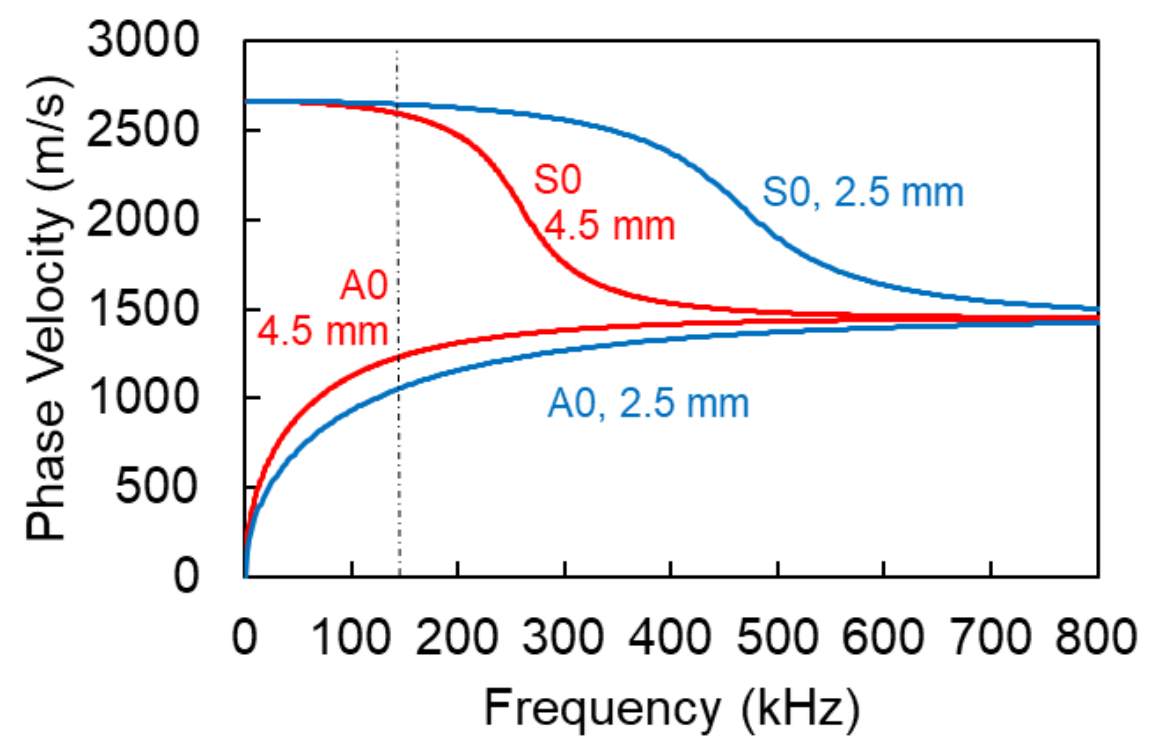

- Dispersion curves for symmetric, S0, and antisymmetric, A0, wave velocities (3000 and $1550 \mathrm{~m} / \mathrm{s}$ ).

- $\mathrm{S} 0$ is expected much faster than $\mathrm{A} 0$ for both cases.

- No strong differences in the onset of the waveforms due to similar velocity of S0.

Frequency $(\mathrm{kHz})$ 


\section{RESULTS}

\section{ARTIFICIAL EXCITATION}

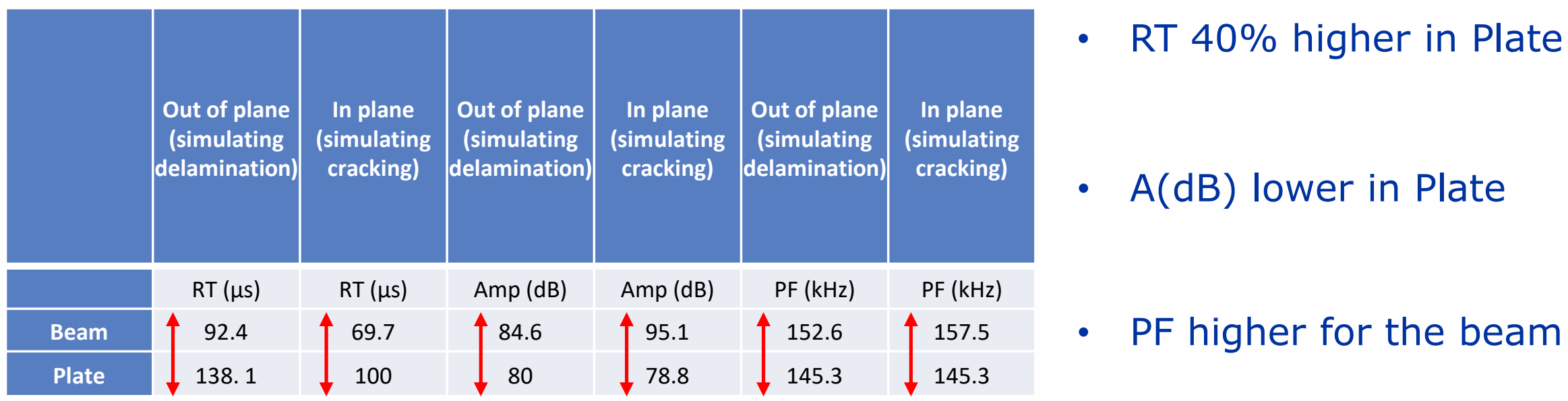

Higher amplitude in beams is interpreted as the effect of immediate reflections ${ }^{1}$ and $1 \mathrm{D}$ propagation in beam contrary to a $2 \mathrm{D}$ propagation in plate. 


\section{RESULTS}

\section{ARTIFICIAL EXCITATION}

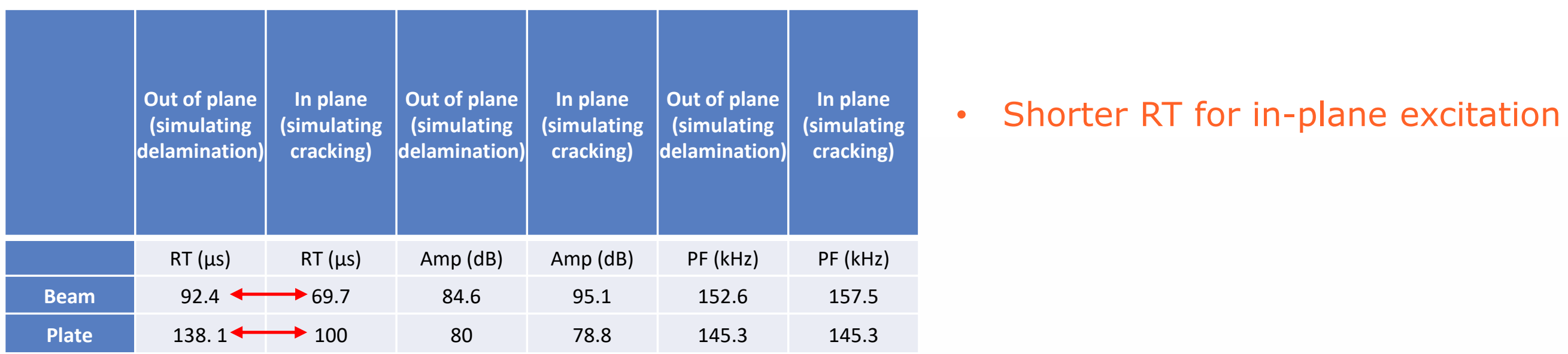

Reasonable due to excitation mode SO(In-plane) is faster than AO(Outof-plane). 


\section{RESULTS}

\section{ARTIFICIAL EXCITATION}
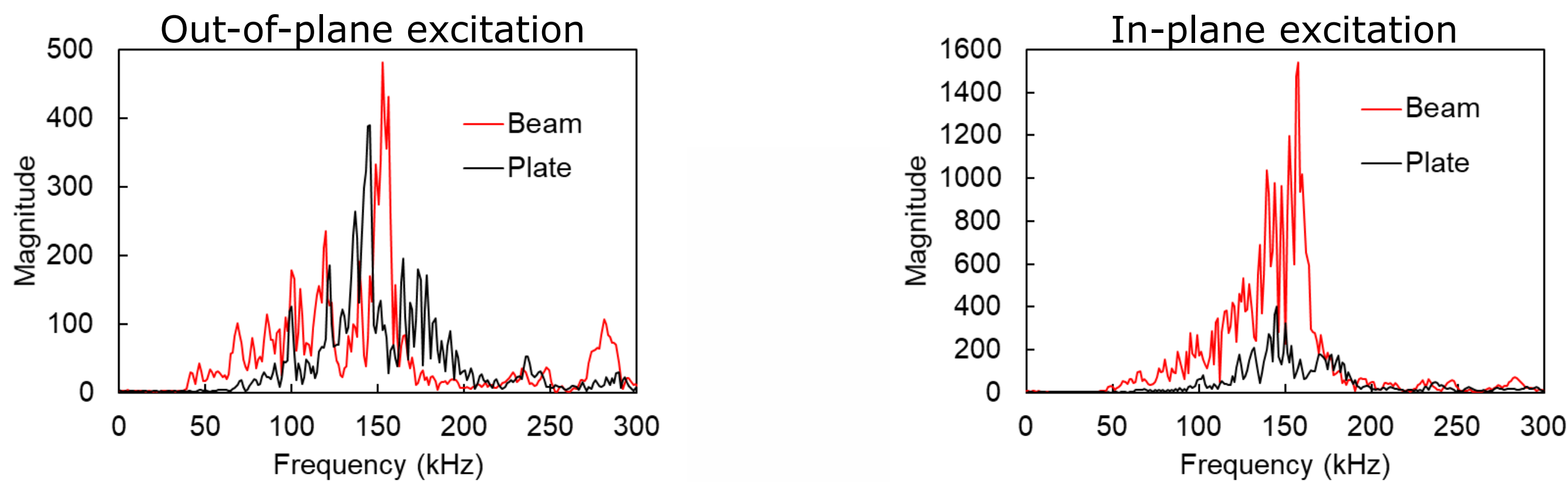

The band of frequencies does not seem to differ much, but the peak is always higher for the beam 


\section{RESULTS}

\section{MECHANICAL TEST}

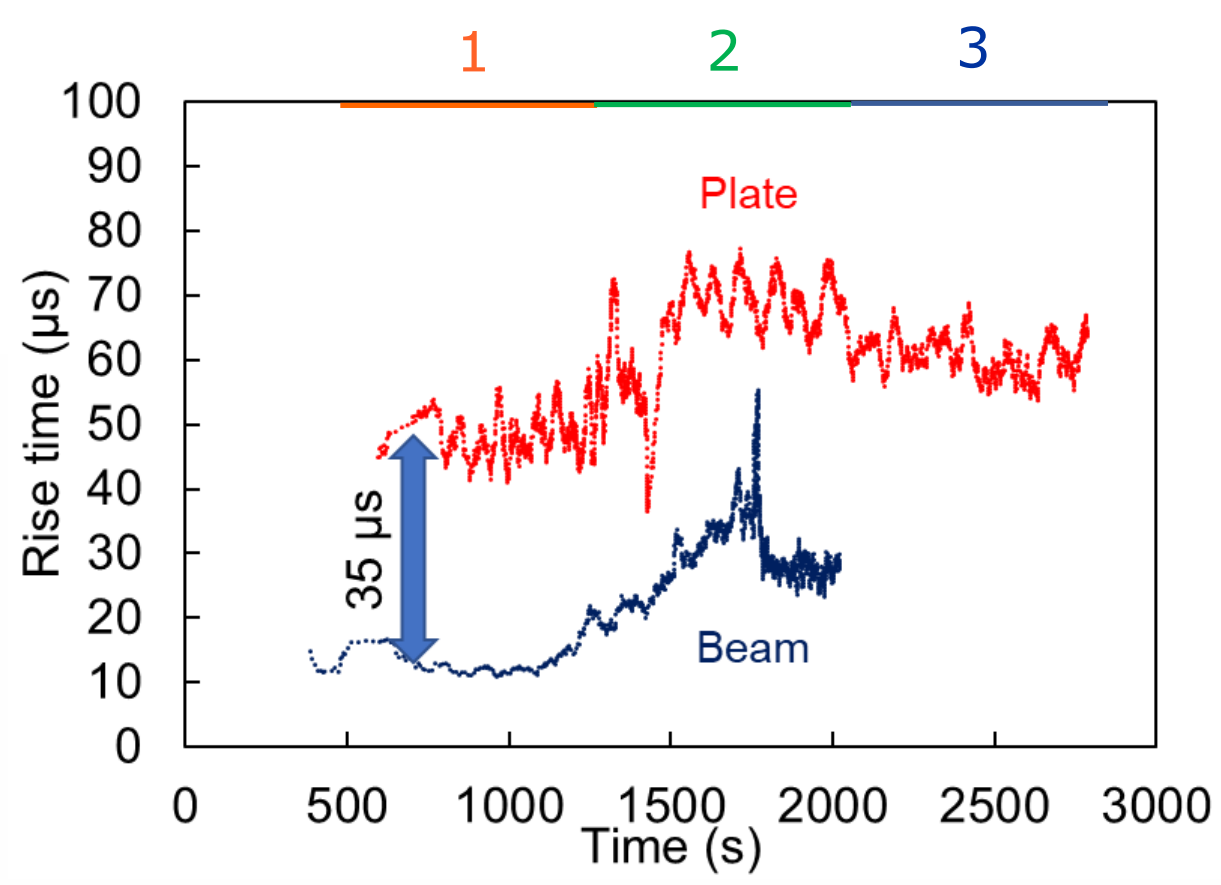

200 points sliding average

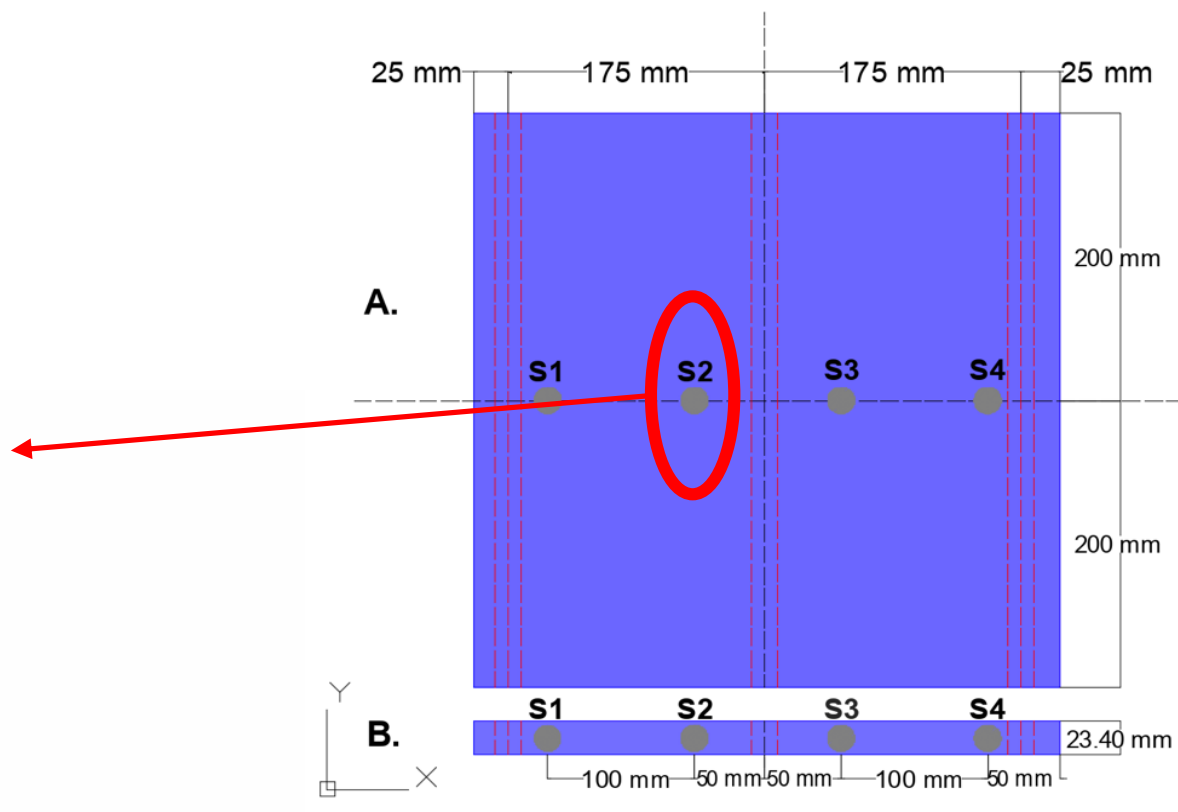

1. Matrix cracking

2. Shift to pull-out and delamination

AE Rise time from real cracking shows the same trend with the artificial sources, it is much higher for the plate specimen 


\section{RESULTS}

\section{MECHANICAL TEST}

Initial $170 \mathrm{kHz}$ AF for the beam

Initial $140 \mathrm{kHz}$ for the plate
Resonant sensors at $150 \mathrm{kHz}$

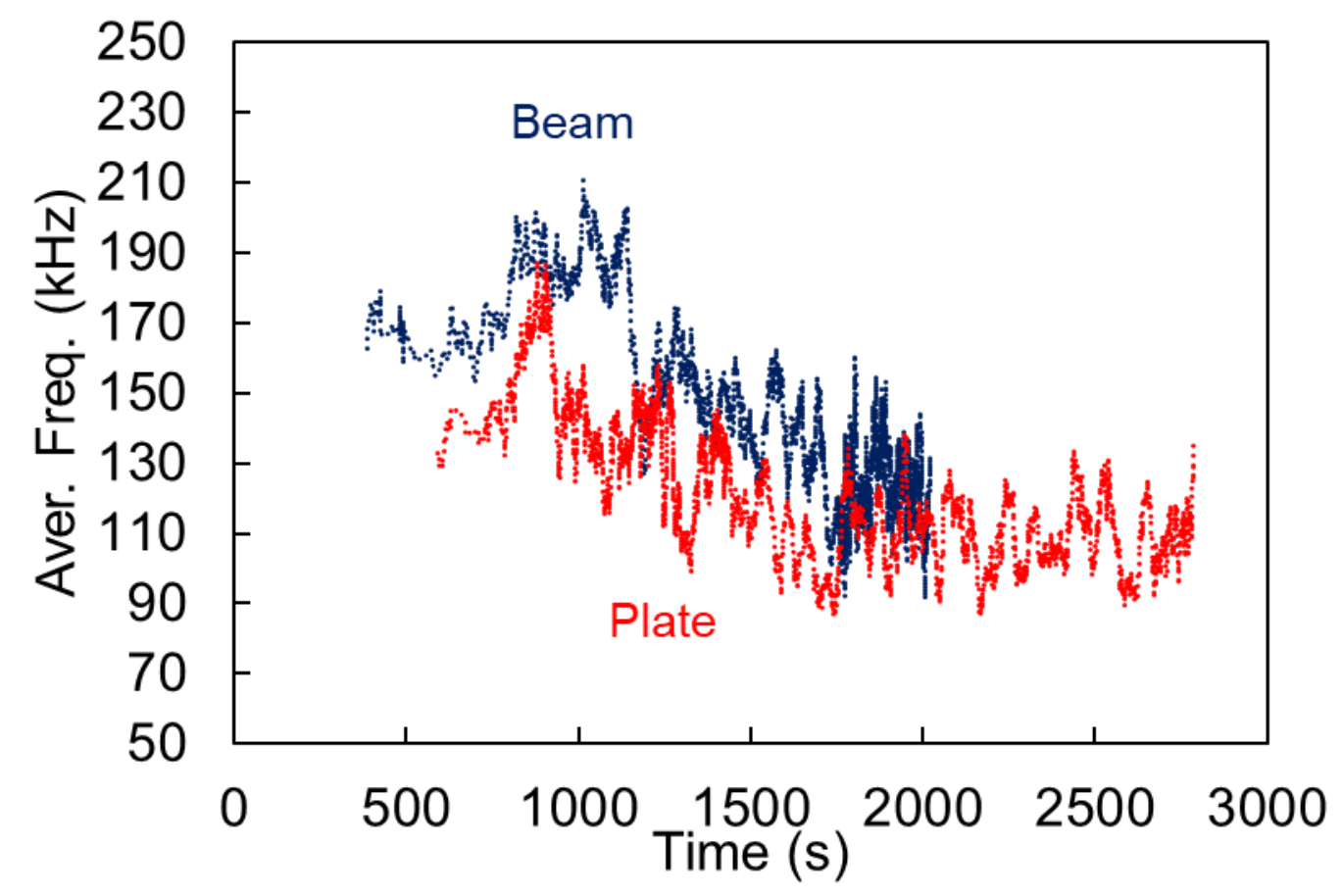

Frequency parameters are higher for the beams showing again similar trends like pencil lead sources. 


\section{RESULTS}

\section{MECHANICAL TEST}
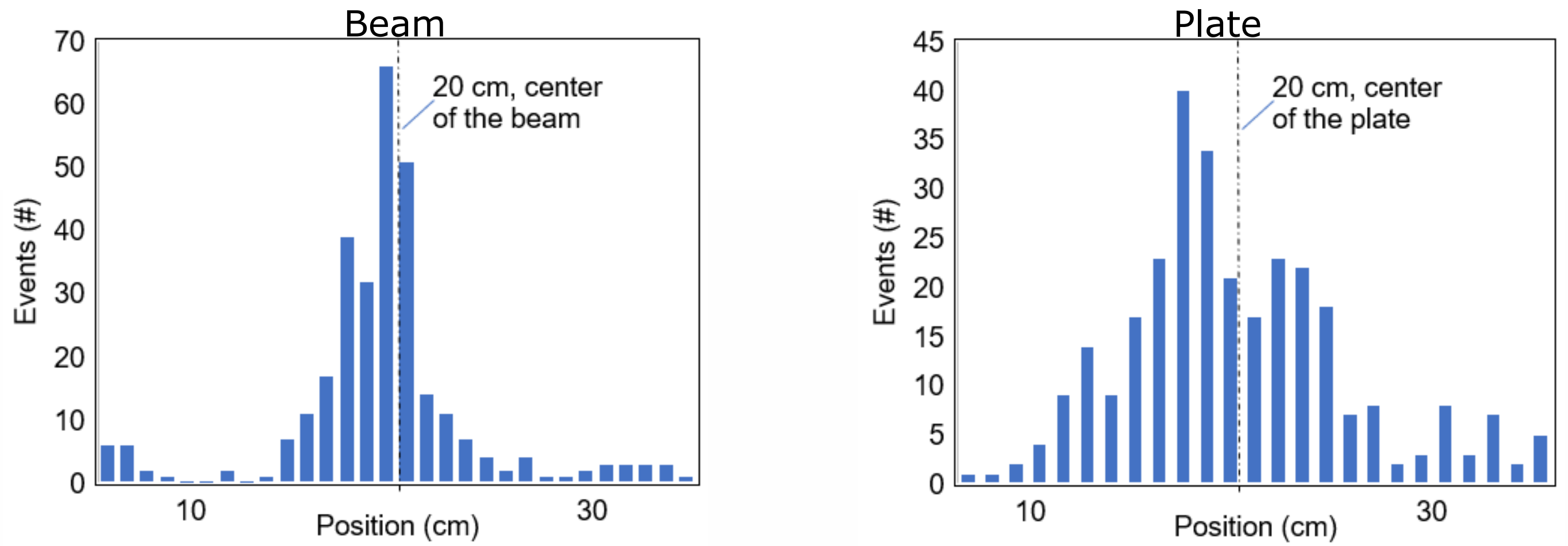

AE localization in both specimens exhibit their peak close to the center, validating the existence of the cracking source on the zone where it is expected. 


\section{RESULTS}

\section{MECHANICAL TEST VS ARTIFICIAL EXCITATION}

(Average values in cracking signals First 300 hits)

\begin{tabular}{|c|c|c|c|c|}
\hline & RT $(\mu \mathrm{s})$ & Amp (dB) & A.F. (kHz) & I.F. (kHz) \\
\hline Beam & 14 & 56.4 & 170.1 & 389.1 \\
\hline Plate & 46 & 60.4 & 136.6 & 274.3 \\
\hline
\end{tabular}

Artificial in-plane excitation

- RT higher in Plate

- $\mathrm{A}(\mathrm{dB})$ higher in Plate

- $A F$ and IF higher for the beam

\begin{tabular}{|c|c|c|c|}
\hline & RT ( $\mu \mathrm{s})$ & Amp (dB) & P.F. (kHz) \\
\hline Beam & 69.7 & 95.1 & 157.5 \\
\hline Plate & 100 & 78.8 & 145.3 \\
\hline
\end{tabular}

- RT higher in Plate

- $A(d B)$ lower in Plate

- PF higher for the beam

For the same type of source (cracking), higher values of RT in the plate could be wrongly

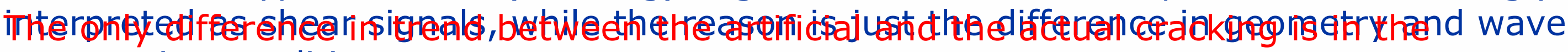
Arapagationirqhditipessanical test is higher in the plate than in the beam. The reason is related to the constrain of a typical crack within the width of the beam, while in plate there is no such limitation $\rightarrow$ higher release of energy 


\section{Conclusions}

\section{(II) \& CONSTRUCTIONS




\section{GENERAL CONCLUSIONS}

- In-plane excitation on a TRC sample (simulating matrix crack) produces shorter AE waveforms than the corresponding out-of-plane excitation (simulating delaminations), clearly showing that fracture mode characterization based on $A E$ is possible in the cementitious composites.

- Plate geometries exhibit longer waveform characteristics like RT and duration, and slightly lower frequency for the same artificial excitation (pencil lead break).

- Cracking signals from actual mechanical testing show the same trends with artificial excitation between beams and plates, with a difference on the energy-related parameters, that seem higher for plates. This is attributed to the unrestricted crack dimensions and propagation increments in the large geometries. 


\section{ACKNOWLEDGMENTS}

1. The financial support of FWO (Fonds Wetenschappelijk Onderzoek-Vlaanderen) through grants G.0337.19N and $\mathbf{1 2 J 7 7 2 0 N}$ is gratefully acknowledged. 


\section{Thank you}

Further questions: Nicolas.ospitia.patino@vub.be

\section{Menc \& CONSTRUCTIONS}

\section{ASEC

